\title{
Activity Patterns of Temperature-reactive Dorsal Horn Neurons and Their Reactions to Peripheral Receptor Stimulation by $\mathrm{Ca}$
}

\author{
Toshiaki NeYA* and Friedlich-Karl PIERAU \\ Max-Planck-Institut für physiologische und klinische Forschung, \\ W. G. Kerckhoff-Institut, 6350 Bad Nauheim, \\ Federal Republic of Germany
}

\begin{abstract}
Unit responses of dorsal horn neurons (DHNs) of rats to thermal stimulation of the scrotal skin were recorded extracellularly. Fifty-five out of 74 DHNs increased their activity during scrotal skin warming, while the activity of 14 neurons was accelerated by cooling. Tonic activities of 3 neurons were inhibited by warming (inverse warmreactive). Two neurons demonstrated a complex response and were activated during cooling and warming. Most of the warm-reactive and all of cold-reactive DHNs had steep sigmoid temperature-activity-relation curves with a temperature-dependent range of $1-5^{\circ} \mathrm{C}$.

Injections of $5-10 \mathrm{mg} / \mathrm{kg} \mathrm{CaCl}$ into the lower abdominal aorta produced excitation in 30 out of 33 warm-reactive DHNs and inhibition in 3 neurons. Only 3 out of 8 cold-reactive DHNs demonstrated inhibition, while the remaining 5 were activated. All three inverse warm-reactive neurons were inhibited. DHNs which exclusively reacted to mechanical stimuli or did not respond to any peripheral stimulation were not affected by peripheral $\mathrm{Ca}$ administration. The results suggest that a number of cold-reactive DHNs receive inputs from warm- and cold-sensitive afferents and that there may exist such double innervation in some warmreactive DHNs as well.
\end{abstract}

A high degree of processing of afferent temperature signals from the scrotal skin at the segmental level of the rat spinal cord has been reported by HeLLON and MisRa (1973a). Whereas receptive fields of mechanoreactive dorsal horn neurons (DHNs) are small and on the ipsilateral side, those of temperaturereactive DHNs are large and bilateral (Hellon and Mrtchell, 1975). The same authors demonstrated a considerable shift of the temperature reaction by clamping the temperature of the contralateral scrotal skin at levels different from

Received for publication May 9, 1980

* Present address: Department of Physiology, Okayama University Medical School, Okayama, 700 Japan

雯屋俊昭 
those of the ipsilateral, suggesting an intense convergency of thermal afferents to temperature-reactive DHNs.

Selective stimulation of peripheral temperature receptors by methods other than thermal stimulation may help to elucidate the mode of temperature signal convergency at the DHN level. For this purpose, alterations of Ca concentration are suggested as a useful means by HENSEL and SCHÄFER (1974), who found that in the cat's infraorbital region, warm receptors were activated and cold receptors were inhibited by intravenous $\mathrm{Ca}$ administration.

The present experiments were designed to compare the effects of thermal stimulation of the scrotal skin and those of injecting small quantities of $\mathrm{Ca}$ into the lower abdominal aorta on temperature-reactive DHNs. The results support the notion that there are DHNs which receive warm- as well as cold-sensitive afferents. Preliminary accounts have been published elsewhere (NEYA and PIERAU, 1975, 1976b).

\section{METHODS}

Male albino rats $(0.35-0.45 \mathrm{~kg})$ were anesthetized with intraperitoneal injection of urethane $(300 \mathrm{mg} / \mathrm{animal})$. Laminectomy was performed between $\mathrm{Th} 13$ and $\mathrm{L} 1$ and the vertebral bones rostral and caudal to the laminectomized region were fixed by clamps. The animals were immobilized with Flaxedil ${ }^{\circledR}$ dissolved in $10 \%$ Macrodex ${ }^{\circledR}$ infused into the femoral vien in a dose of $6 \mathrm{mg} / \mathrm{animal} / \mathrm{h}$, and were artificially ventilated. A unilateral pneumothorax was sometimes performed to minimize movements due to respiration. The exposed spinal cord was covered with liquid paraffin maintained at about $37.5^{\circ} \mathrm{C}$ by means of a watercirculated metal coil. Rectal temperature was maintained at $38 \pm 0.5^{\circ} \mathrm{C}$ by a water-perfused heating pad. Carotid blood pressure and ECG were monitored and blood pressure was kept at above $80 \mathrm{mmHg}$ by adjusting the rate of Macrodex infusion.

Activities of single DHNs were recorded by means of glass microelectrodes filled with Pontamine sky blue dissolved in $0.5 \mathrm{M} \mathrm{Na}$ acetate. The dye could be deposited by iontophoresis for marking the tip position (Hellon, 1971). The electrode tips were carefully broken to reduce resistances to values between 12 and $18 \mathrm{M} \Omega$. Extracellular unit discharges were amplified by a preamplifier (WPI, M 701), separated by a window discriminator (WPI, Mod. 120) and counted by a rate meter over a suitable time (Frederic Haer). Bioelectric data together with blood pressure and scrotal temperature were simultaneously stored on a tape recorder (Bell and Howell 3020) and a chart recorder (Rikadenki). Recordings were undertaken at the spinal cord at L 6 and S 1 . Histological control revealed that discharges of DHNs were recorded from lamina II-IV, predominantly from laminae III and IV (Rexed).

To examine the temperature reactivity of DHNs, the temperature of the scrotal skin was warmed or cooled by flowing water of different temperatures 
through a hollow metal thermode $(35 \times 35 \times 5 \mathrm{~mm})$ built to conform to the ventral surface of scrotum. The thermode covered about $65 \%$ of the total area of scrotal skin. Sensitivity of DHNs to mechanical stimulation was examined by stroking the scrotal and hind leg skin with a glass rod or by flexing the ipsilateral hind leg. Effects of $\mathrm{Ca}$ on DHN activity were examined by injecting a solution of $\mathrm{CaCl}_{2}$ at a rate of 3 to $10 \mathrm{mg} / \mathrm{kg} / 15 \mathrm{sec}$ into the bifurcation of the lower abdominal aorta via a catheter in the contralateral femoral artery (the arterial supply of the lumbar cord is upstream to this injection site). We assumed that $\mathrm{Ca}$ would effectively be diluted before it arrived at DHNs via the systemic circulation so that its direct effect on them would be negligible.

\section{RESULTS}

Temperature reaction of warm-reactive DHNs

As observed by HELLON and MisRa (1973a), the response of the warm-reactive neurons was divided into three types; static, dynamic, and dynamic/static. The frequencies of incidence are highest for the static response and lowest for the dynamic response, being intermediate for the dynamic/static response (Table 1).

Table 1. Response of temperature-reactive DHNs to temperature stimulation of the scrotal skin.

\begin{tabular}{lcccc}
\hline & Warm & Cold & $\begin{array}{c}\text { Inverse } \\
\text { warm }\end{array}$ & $\begin{array}{c}\text { Warm } \\
\text { and cold }\end{array}$ \\
\hline Dynamic/static response & $16(2)[2]$ & 2 & & 2 \\
Static response only & $30(2)[1]$ & $12(1)$ & 1 & \\
Dynamic response only & 9 & & 2 & 2 \\
Total & $55(4)[3]$ & $14(1)$ & 3 & 2 \\
\hline
\end{tabular}

( ), mechanoreactive skin; [ ], mechanoreactive muscle.

This is in contrast to the finding of HeLlon et al. (1975) that in the peripheral temperature-sensitive afferents only the dynamic/static response is seen, though this was not confirmed by other investigators (PIERAU et al., 1975). In DHNs showing the static response, the activity steeply increased during warming without any phasic overshoot; this increase was largely independent of the rate of the temperature change (Fig. 1A). Then the discharge usually further increased to a higher level. The decline of activity with a fall of temperature was usually somewhat slower than the increase of activity.

It was usually observed that the reaction of DHNs to scrotal temperature changes had a distinct threshold. In the example of Fig. 1A, a warming step from 37.5 to $41^{\circ} \mathrm{C}$ elicited an increase of DHN activity but an even larger step in the lower range between 33 and $37.5^{\circ} \mathrm{C}$ did not produce any neuronal activity. The threshold phenomenon was also observed in other types of neurons such as purely phasic reactive DHNs (Fig. 1B) or inverse warm-reactive DHNs (Fig. 2). 

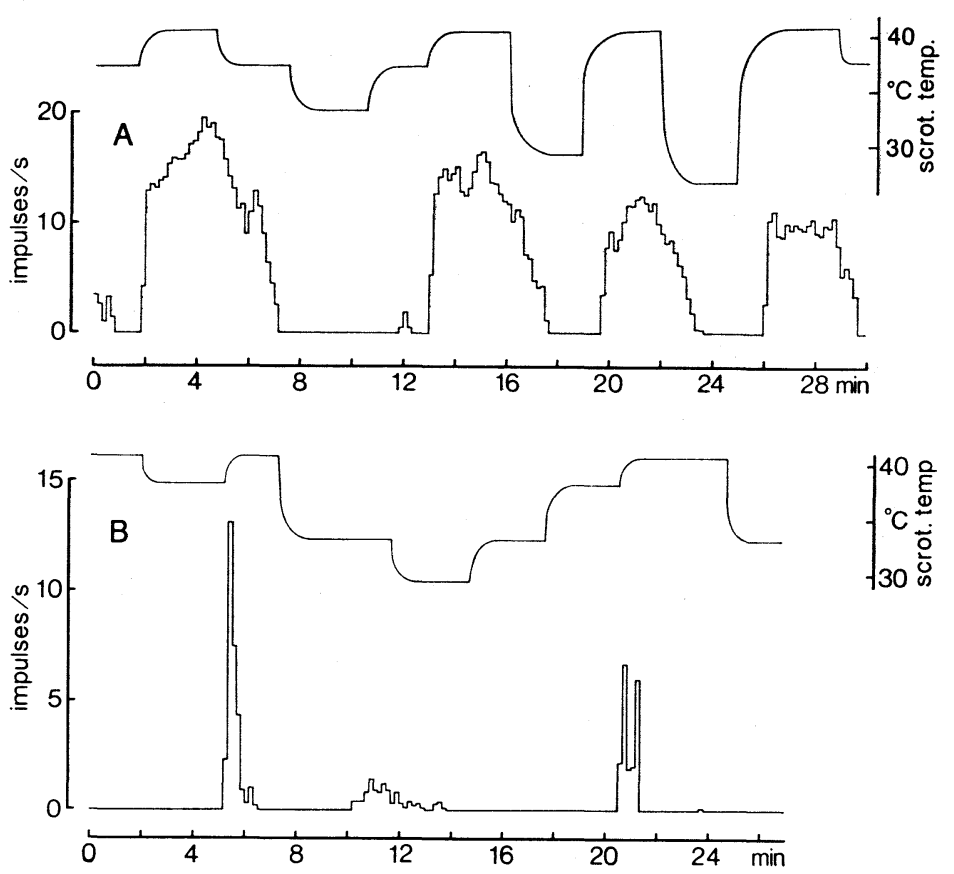

Fig. 1. Two warm-reactive DHNs demonstrating a purely static (A) and a purely dynamic activation (B) to scrotal skin warming.

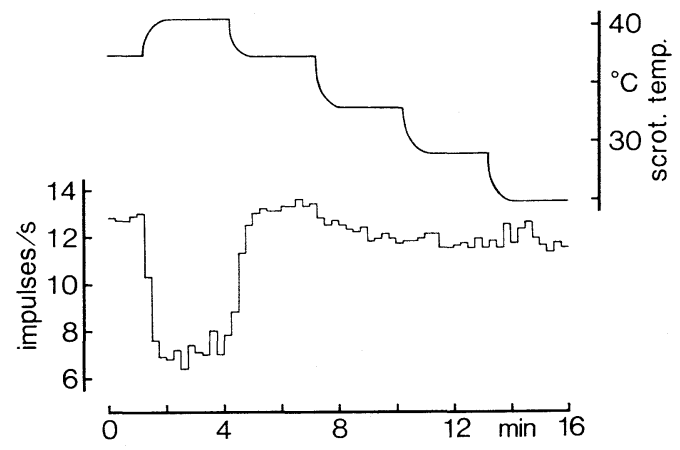

Fig. 2. Responses of an inverse warm-reactive $\mathrm{DHN}$ at different temperatures of the scrotal skin.

Three neurons were identified as inverse warm-reactive because the scrotal skin warming produced an inhibition and the cooling restored the intrinsic activity in the pre-warming period without inducing any facilitation (HELLON and MISRA, 1973a).

Figure 3 shows the static activity of 29 neurons of the static and dynamic/ static warm-reactive type as a function of the scrotal temperature. In most of 


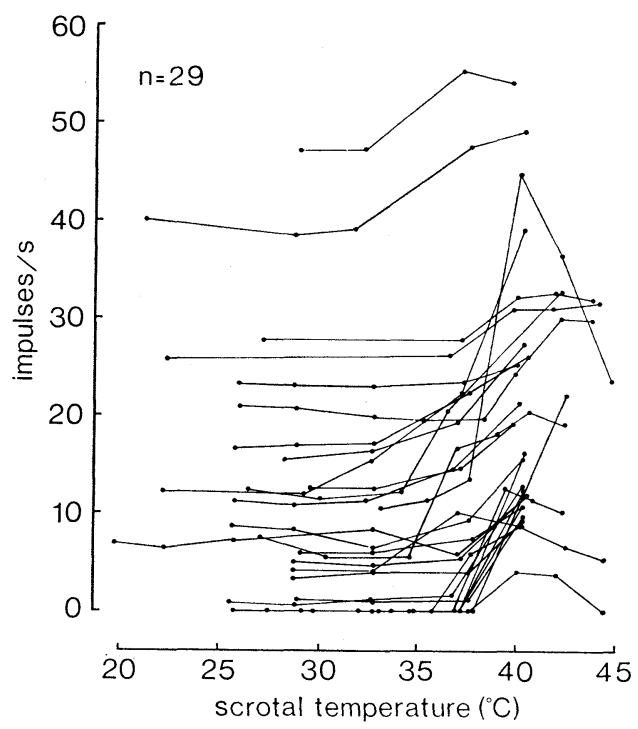

Fig. 3. Impulse activity of 29 warm-reactive DHNs as a function of stationary scrotal skin temperature. Plotted points represent mean firing rates over the last $30 \mathrm{sec}$ at each temperature.

them there were no marked changes in the activity level insofar as the scrotal temperature remained below $37^{\circ} \mathrm{C}$. However, as the scrotal temperature increased above $37^{\circ} \mathrm{C}$, the activity steeply increased. In a number of neurons the temperature reaction occurred within a small operating range of 2 to $3^{\circ} \mathrm{C}$. This is similar to the responses of cold-reactive DHNs to temperature change of scrotal skin (PIERAU et al., 1980). This type of response was first described by Hellon and MisRA (1973b) for thalamic neurons.

In a few neurons the temperature-dependent range was extended to more than $5^{\circ} \mathrm{C}$. However, determination of the firing rate at scrotal temperatures above $40^{\circ} \mathrm{C}$ was often impeded by a loss of temperature reaction, a finding which was also reported for warm-sensitive neurons of the cat's face (Sumino et al., 1973). In the remaining DHNs the temperature-activity-relation was a bellshaped curve which in some respects resembled the temperature-response curve of primary temperature-sensitive afferents (Hellon et al., 1975). However, unlike peripheral receptors having the bell-shaped temperature-activity curve, the warm-reactive DHNs usually did not cease to discharge at scrotal skin temperatures below $30^{\circ} \mathrm{C}$ and maintained about the same level of activity independent of skin temperature in this range.

\section{Temperature reaction of cold-reactive DHNS}

The response of cold-reactive DHNs to peripheral temperature stimuli appeared as the mirror image of the responses of warm-reactive DHNs. The reac- 

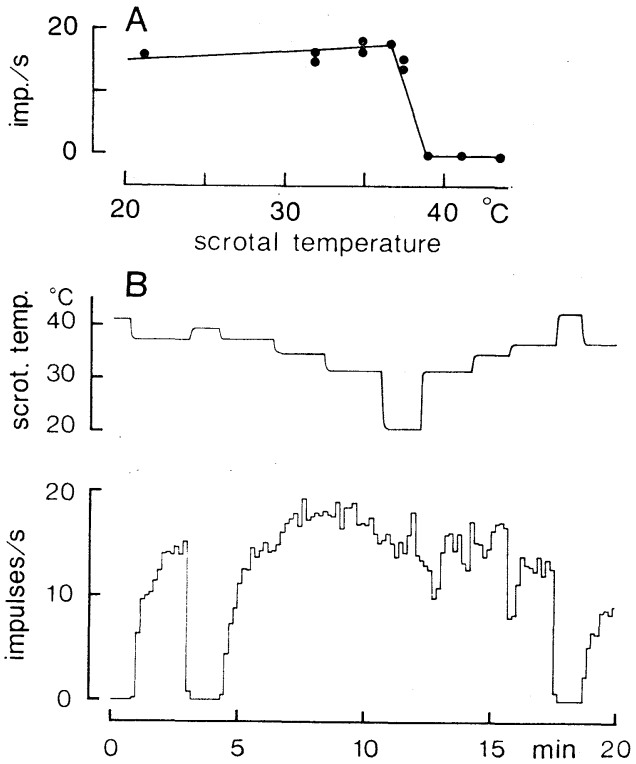

Fig. 4. Impulse activity of a cold-reactive DHN, demonstrating a static activation to scrotal skin cooling. A, impulse frequency as a function of the scrotal skin temperature; $\mathrm{B}$, response to step warming and cooling.

tion to scrotal temperature changes appeared only when the latter was lowered below certain thresholds (about $38^{\circ} \mathrm{C}$ in the example of Fig. 4). The step-like change of activity to temperature stimulation was more distinct than in warmreactive DHNs. None of the cold-reactive neurons exhibited bell-shaped, temperature-response curves (PIERAU et al., 1980). As is demonstrated in Fig. 4, the operating range was generally smaller $\left(1-3^{\circ} \mathrm{C}\right)$ than in warm-reactive neurons. Most of the cold-reactive DHNs (Table 1) expressed purely static reactions to sudden temperature changes; no purely dynamic response was observed. Two neurons (not illustrated) demonstrated a rather complex response, suggesting that they probably receive inputs from both warm- and cold-sensitive afferents. One of these neurons showed an increase of the static activity to cooling below $30^{\circ} \mathrm{C}$ and a phasic increase of activity to sudden warming. The other demonstrated a biphasic response to a warming step from 38 to $42^{\circ} \mathrm{C}$; it was first inhibited transiently and then facilitated.

Similar to the observations of HeLlon and MisRa (1973a), we did not find any good correlation between the recording sites and neuron types. Particularly, neurons demonstrating dynamic/static activity were found to be not restricted to lamina II where C-fibers are thought to terminate (WILLIS and CoGGESHALL, 1978). On the other hand, purely static reactions were observed in DHNs superficially located in the dorsal horns. 


\section{Indirect effect of intraarterial Ca administration on DHNS}

The effects of intraarterially administered $\mathrm{Ca}$ ions on 60 DHNs are summarized in Table 2. Thirty-six of the 44 temperature-reactive neurons were warm-reactive and 8, cold-reactive. Eleven neurons not responding to scrotal temperature stimuli were sensitive to gentle mechanical stimulation of the scrotal skin or hind limb. The remaining 5 neurons were insensitive to both thermal and mechanical stimuli.

Table 2. Indirect effect of $\mathrm{Ca}$ ions on temperature-reactive DHN.

\begin{tabular}{lcccc}
\hline \multicolumn{1}{c}{ Type of response } & Number & Excitation & Inhibition & No effect \\
\hline Warm-reactive & 33 & $30[7](7)$ & 3 & 0 \\
Inverse warm-reactive & 3 & 0 & 3 & 0 \\
Cold-reactive & 8 & $5[2]$ & 3 & 0 \\
Mechanoreactive & 11 & 0 & 0 & 11 \\
Nonthermo- and non- & & & & \\
$\quad$ mechanoreactive & 5 & 0 & 0 & 5 \\
Total & 60 & $35[9](7)$ & 9 & 16 \\
\hline
\end{tabular}

[ ], biphasic reaction; ( ), mechanoreactive.

In all temperature-reactive neurons, the impulse frequency changed after injection of $3-10 \mathrm{mg} / \mathrm{kg}$ of $\mathrm{CaCl}_{2}$ into the lower abdominal aorta with a latency ranging from 2 to $5 \mathrm{sec}$ (Fig. 5A). This short latency suggests that the activity change of DHNs is secondary to the direct action of $\mathrm{Ca}$ on the peripheral receptors. Although the circulation time was not determined, one would expect a delay of about $10 \mathrm{sec}$ if $\mathrm{Ca}$ acted upon DHNs directly, since injections of $\mathrm{Ca}$ into the femoral vein became effective after a latency of 8 to $12 \mathrm{sec}$ (five experiments). In contrast, $\mathrm{Ca}$ in a dose of 5 to $15 \mathrm{mg} / \mathrm{kg}$ administered into the lower abdominal aorta did not affect purely mechanoreactive DHNs (Fig. 5B) nor those which were not influenced by peripheral stimuli (Fig. 5C).

\section{Warm-reactive DHNS}

In Fig. 6 is shown a typical reaction of a warm-reactive DHN to a warming step applied to the scrotal skin. Intraarterial injection of 5 or $10 \mathrm{mg} / \mathrm{kg} \mathrm{Ca}$ produced an expected increase of neuronal activity.

The majority of warm-reactive DHNs ( $n=30$, Table 2$)$ demonstrated a transient increase of spike frequency (usually lasting 1-2 min) after peripheral $\mathrm{Ca}$ administration. The degree of acceleration was largely independent of the scrotal temperature at the time of $\mathrm{Ca}$ injection (Fig. 6A) or of the types of the temperature reaction. In $6 \mathrm{DHNs}$, exhibiting the dynamic/static or the dynamic warm reaction, the $\mathrm{Ca}$-induced increase of firing frequency was followed by a transient inhibition (Fig. 6B). This is similar to the Ca effect on peripheral warm receptors reported by HENSEL and SCHÄFER (1974). In 5 cases this reduction of activity remained the same for up to $1 \mathrm{~min}$ at high scrotal temperatures $\left(41-43^{\circ} \mathrm{C}\right.$; Fig. $\left.6 \mathrm{~B}\right)$. 

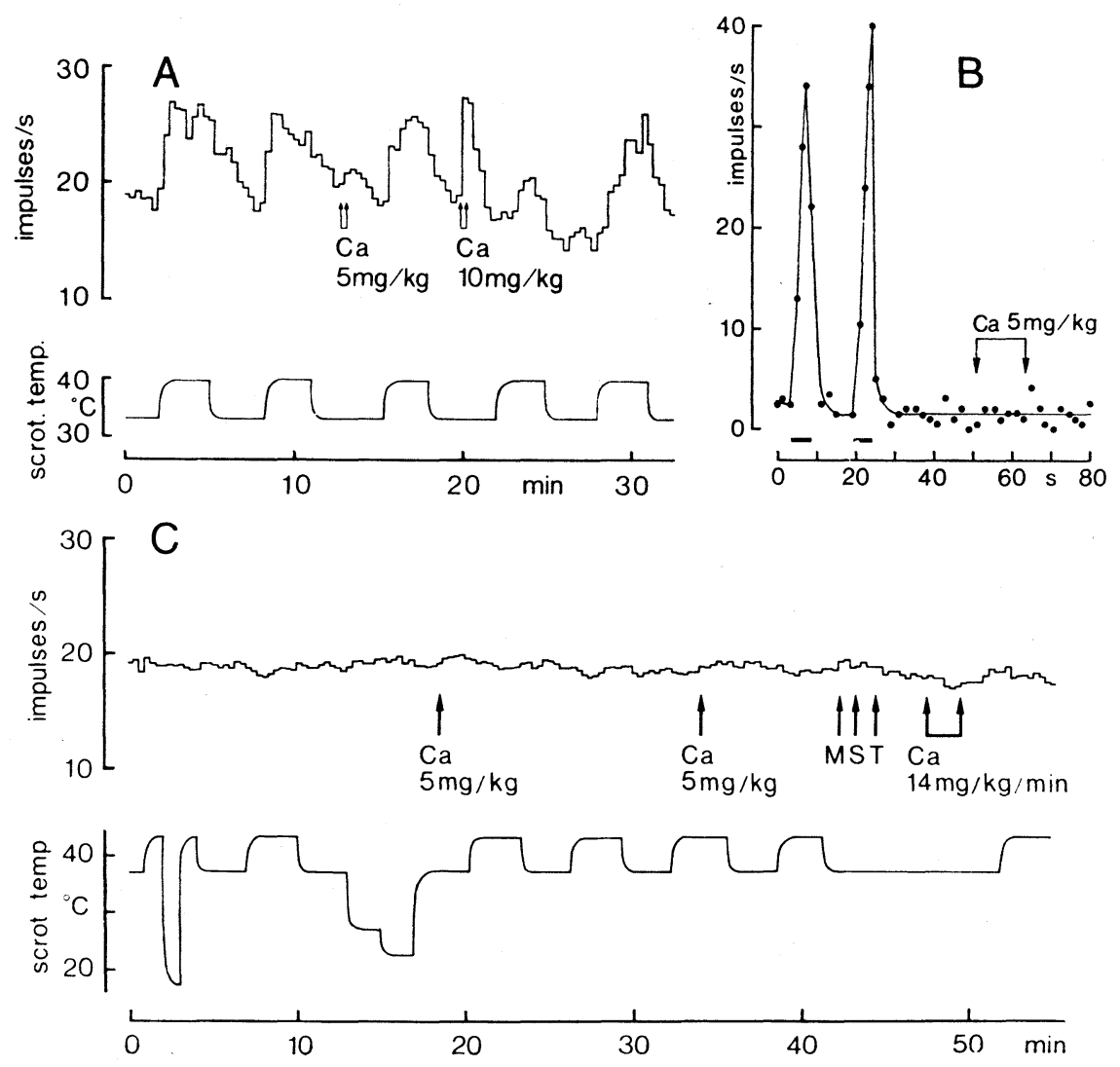

Fig. 5. Activity of 3 different DHNs after administration of $\mathrm{Ca}$ into the lower abdominal aorta. A, warm-reactive neuron; B, mechanoreactive neuron; $\mathrm{C}$, neuron not responding to peripheral stimuli. Only the temperature-reactive DHN responded to Ca administration. MST, mechanical stimuli.

Convergency of mechanosensitive afferents to warm-reactive DHNs did not affect the reaction to Ca. Five of the 7 warm-reactive DHNs which also responded to peripheral mechanical stimulation demonstrated a pure excitation to $\mathrm{Ca}$ administration, while the remaining two exhibited a biphasic excitatory/inhibitory reaction.

However, in 3 warm-reactive DHNs, intraarterial administration of $\mathrm{Ca}$ caused a marked transient inhibition which was not preceded by facilitation. In one of these the inhibition was followed by a transient acceleration. In another DHN Ca produced different reactions at different temperatures; a transient acceleration at $36.8^{\circ} \mathrm{C}$ but an inhibition at $40.5^{\circ} \mathrm{C}$ (Fig. 7A).

$\mathrm{Ca}$ produced also a pure inhibition in the 3 inverse warm-reactive DHNs. Figure $7 \mathbf{B}$ demonstrates that this inhibition was independent of the scrotal skin temperature. 

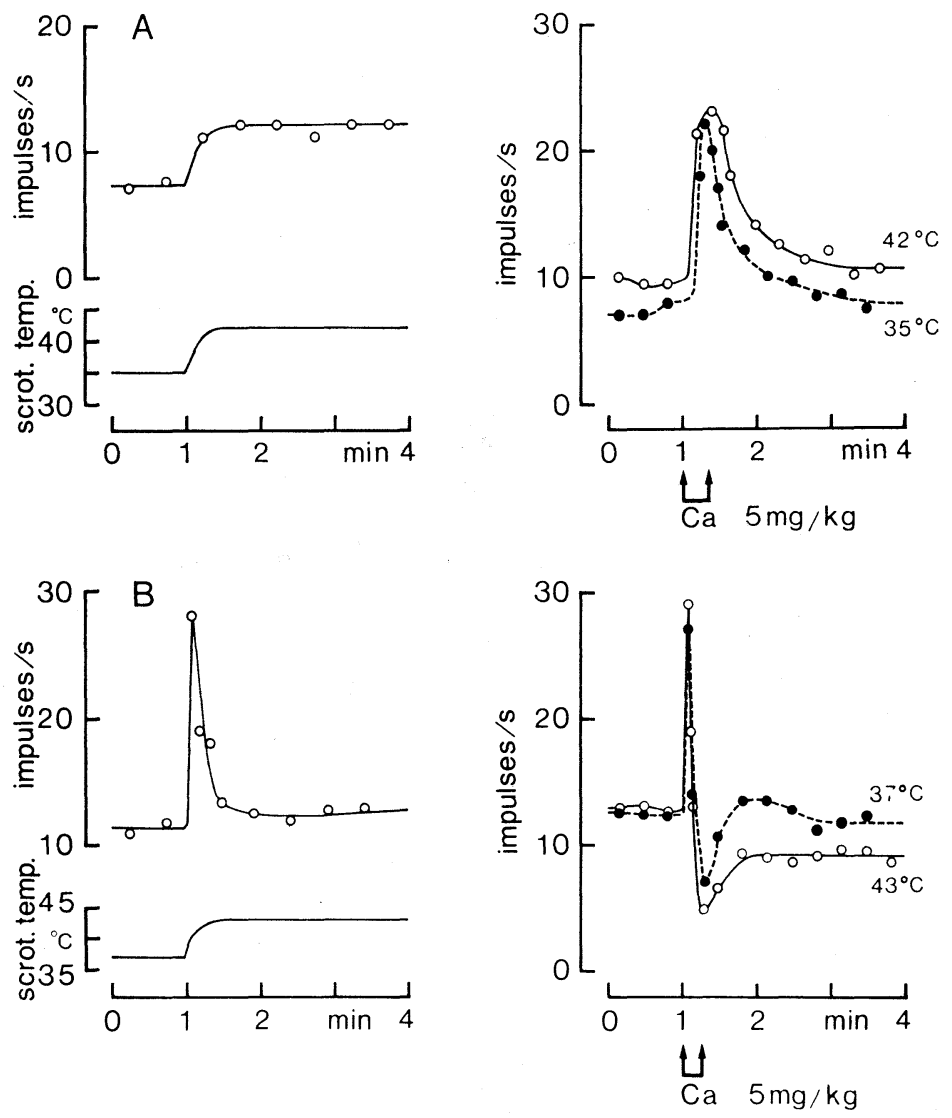

Fig. 6. Temperature-reaction (left) and excitatory reaction to $\mathrm{Ca}$ administration (right) of 2 different warm-reactive DHNs. Ca produced a transient acceleration in $\mathrm{A}$ and an acceleration followed by an inhibition in B. No quantitative differences are found in the $\mathrm{Ca}$ response at different scrotal skin temperatures.

\section{Cold-reactive DHNS}

While the majority of warm-reactive DHNs responded to peripheral $\mathrm{Ca}$ administration with the increase of activity, a greater part (5 out of 8 ) of coldreactive DHNs did not demonstrate an anticipated inhibition but increased their spike frequency after intraarterial $\mathrm{Ca}$ injection. Figure $8 \mathrm{~A}$ gives an example of a cold-reactive $\mathrm{DHN}$ which was temporarily inhibited after the $\mathrm{Ca}$ injection. Type and degree of the reaction were largely independent of the actual temperature at the peripheral receptor.

Three of the neurons whose activities were accelerated by peripheral $\mathrm{Ca}$ injection showed a monophasic transient response which largely disappeared after 1-2 min (Fig. 8B). The other two neurons of this type showed a monophasic response at high receptor temperatures (low spontaneous frequency), but demon- 

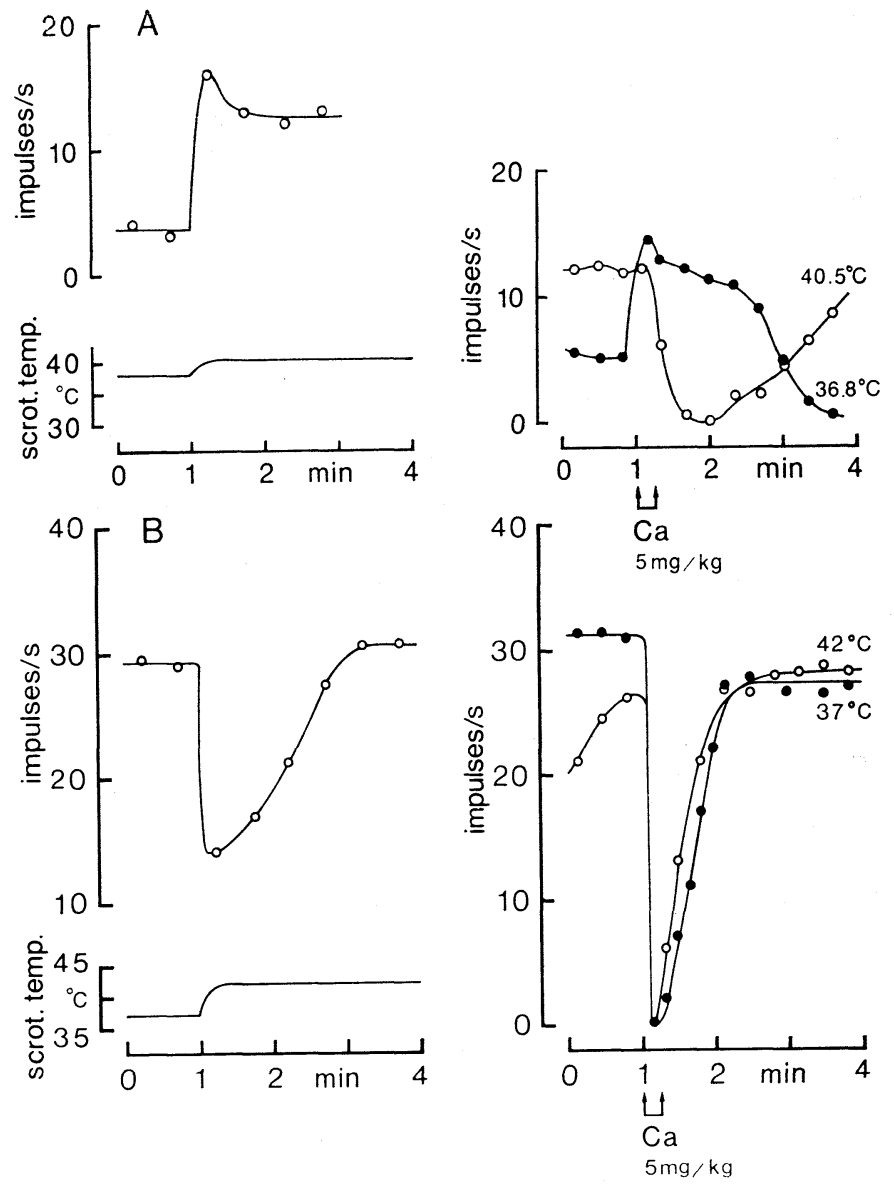

Fig. 7. Temperature-reaction (left) and reaction to $\mathrm{Ca}$ administration (right) of a warmreactive (A) and an inverse warm-reactive DHN (B). Ca-induced response in A was excitatory at $36.8^{\circ} \mathrm{C}$ but inhibitory at $40.5^{\circ} \mathrm{C}$. The inhibitory response to $\mathrm{Ca}$ in $\mathrm{B}$ was independent of scrotal temperature.

strated a biphasic inhibitory/excitatory reaction at low receptor temperatures (high control activity) (Fig. 8C).

No relationship was found between the type of reaction to $\mathrm{Ca}$ and the location of temperature-reactive DHNs. Particularly, the neurons which demonstrated a paradoxical reaction to $\mathrm{Ca}$ were distributed within all layers of the dorsal horn.

\section{DISCUSSION}

Site of action of $\mathrm{Ca}$ ions. The present experiments are based on the assumption that $\mathrm{Ca}$ ions administered into the lower abdominal aorta in a dose of $5 \mathrm{mg}$ / 

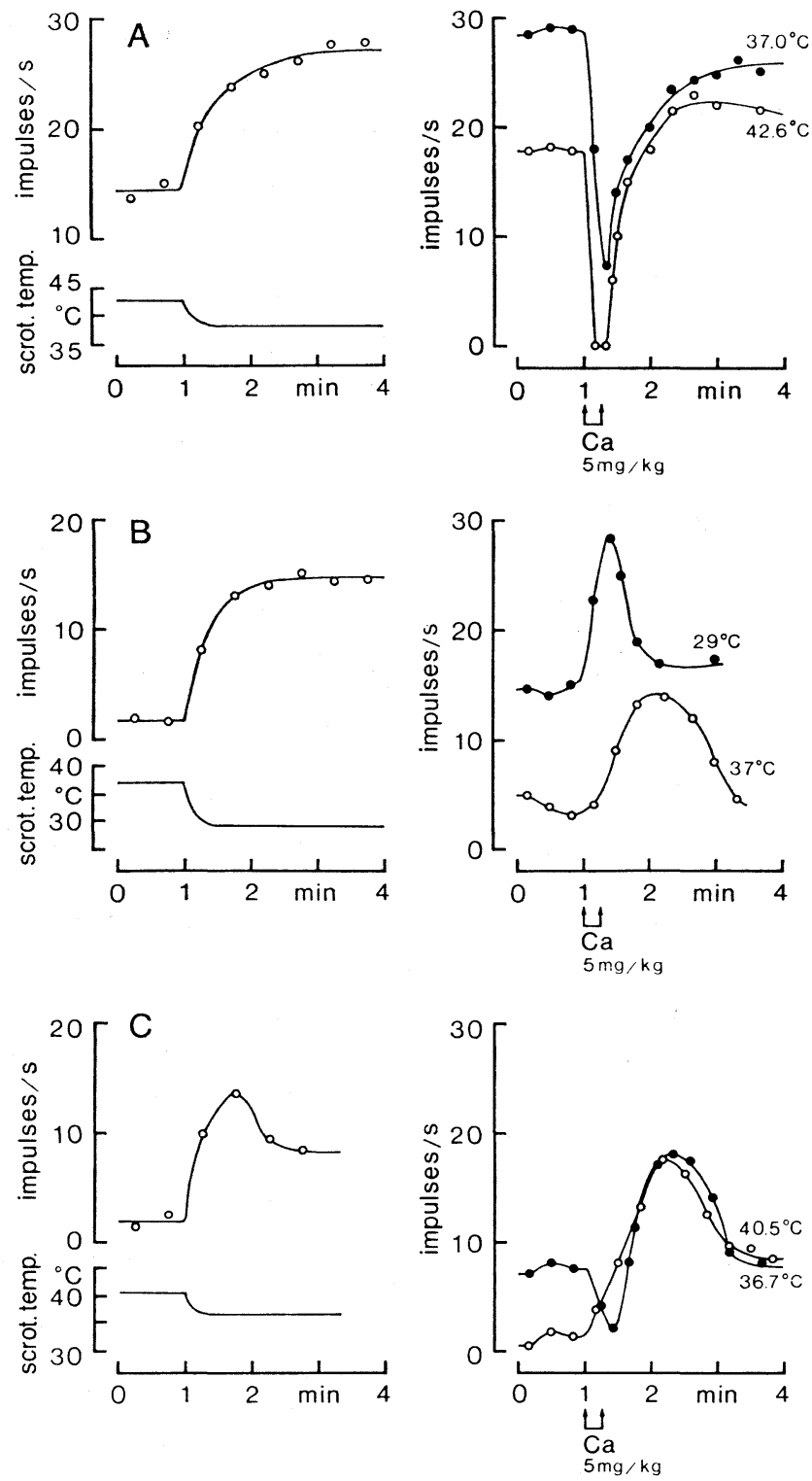

Fig. 8. Temperature-reaction (left) and reaction to the administration of Ca (right) of 3 different cold-reactive DHNs. Ca produced a transient inhibition in A but a transient acceleration in B and C. Acceleration in C was preceded by a short inhibition at $36.7^{\circ} \mathrm{C}$. There were no quantitative differences of the $\mathrm{Ca}$-induced response at different scrotal temperatures. 
$\mathrm{kg}$ exclusively operate on the receptor site but not on the DHNs themselves nor on other central neurons which project to temperature-reactive DHNs, i.e., all the described $\mathrm{Ca}$ effects on DHNs are assumed to be mediated by the afferent inputs.

There are several pieces of indirect evidence for this assumption; 1) The latency of the response to $\mathrm{Ca}$ administration $(2-5 \mathrm{sec})$ appears too short to be accounted for as due to a direct action on DHN. 2) Ca of less than $10 \mathrm{mg} / \mathrm{kg}$ produced an effect exclusively on those units which received inputs from thermosensitive afferents. 3) That reactions of the same temperature-reactive DHNs to $\mathrm{Ca}$ differ at different temperatures of the scrotal skin can hardly be attributed to a direct action of $\mathrm{Ca}$ on the DHN.

Regarding point 2, we have to account for the fact that mechanoreactive DHNs were not affected by peripheral $\mathrm{Ca}$ administration, since $\mathrm{Ca}$ is also reported to reduce responses of vibrissa receptors of cats and other mechanoreceptors (FITZGeRALD, 1940; NIER, 1974). The most important argument appears to be that most peripheral mechanoreceptors do not show spontaneous activity but show phasic response when stimuli are applied. Consequently, responses to $\mathrm{Ca}$ administration of mechanoreactive DHNs, if any, are difficult to detect.

Comparison of the Ca response of temperature receptors and DHNs. The response of the majority of the warm-reactive and some cold-reactive DHNs to intravascularly administered $\mathrm{Ca}$ were very similar to the $\mathrm{Ca}$-induced reactions of peripheral temperature receptors reported by HENSEL and SCHÄFER (1974); Ca produced a transient excitation in the warm-reactive DHNs and a transient inhibition in some cold-reactive DHNs. According to HENSEL and SCHÄFER (1974), effects on peripheral receptors of intravenously administered $\mathrm{Ca}$ were shortlasting $(10-20 \mathrm{sec})$. In contrast, the present experiment showed that $\mathrm{Ca}$-induced frequency changes in DHNs continued for 1-3 min. Such long-lasting modification of DHN activity by Ca may be explained by the fact that since we administered $\mathrm{Ca}$ intraarterially, it could act upon peripheral receptors more intensively than by intravenous administration. Actually, Ca injection into the lingual artery produced an inhibition of lingual cold receptors lasting 1-2 min (PIERAU and WuRSTER, 1975). Furthermore, although in peripheral warm receptors the $\mathrm{Ca}$ effect is known to differ according to the skin temperature (HENSEL and SCHÄFER, 1974), such was not observed in DHNs. This might reflect a high degree of processing of different temperature signals at the segmental spinal level as found in the present experiments and in those by Hellon and MisRa (1973a) and Hellon and MitCHELL (1975).

There is a similarity of the $\mathrm{Ca}$ reaction in the majority of warm-reactive DHNs and peripheral warm receptors. Inputs to the warm-reactive DHNs are suggested to be almost homogenous in the sense that they receive afferents almost exclusively from the warm receptors. Since 3 inverse warm-reactive DHNs were inhibited by $\mathrm{Ca}$ administration in the same way as they were inhibited by scrotal 
warming, their inputs would be homogeneous.

However, in 3 out of 30 warm-reactive DHNs and in 5 out of 8 cold-reactive ones, the responses to $\mathrm{Ca}$ did not conform to the fact that in the periphery $\mathrm{Ca}$ excites warm receptors and inhibits cold ones. It is assumed that inputs to these neurons are inhomogeneous; warm-reactive DHNs receive inputs not only from warm receptors but also from cold receptors while cold-reactive DHNs receive inputs not only from cold receptors but also from warm receptors.

Yamasato and Pierau (1979) demonstrated that some DHNs were activated or inhibited maximally at two temperature ranges which considerably differed from each other. Though this observation was not based on pharmacological differentiation, it is suggested that inputs to some DHNs are not homogeneous. Similarly, the present results that two DHNs showed complex reactions to peripheral temperature changes and some temperature-reactive DHNs showed different reactions to $\mathrm{Ca}$ at different scrotal temperatures (Figs. 7A and $8 \mathrm{C}$ ) suggest converging inputs of different types of temperature-sensitive afferents to one DHN.

Assuming that a number of temperature-reactive DHNs receive inputs from different types of temperature receptors, it remains obscure why the inputs determining the reaction of a DHN to peripheral temperature stimulation are different from those causing the reaction to peripheral $\mathrm{Ca}$ administration. The type of reaction of a DHN receiving multiple inputs is probably determined by quantitative or qualitative predominance of particular afferents. Since the effect of temperature stimulation is restricted to the skin area under thermal control, the thermal stimulus might sometimes not affect all the converging receptors, while $\mathrm{Ca}$ might influence a high percentage of the receptors. In this respect, the biphasic reaction to $\mathrm{Ca}$ might reflect delays of drug action caused by different time courses of the transportation of the ion to individual receptors by the local circulation.

Nevertheless, our results suggest that most of the warm-reactive neurons receive a relatively uniform input from warm-sensitive afferents. On the other hand, spinal convergency of different temperature inputs appears to be quite frequent in the afferent pathway of cold signals from the scrotal skin. This might be of consequence for the central processing of temperature signals at the segmental level. For example, vasomotor changes are reported to correspond well to acceleration of warm-reactive DHNs but not to activation of cold-reactive DHN in rats (Neya and Pierau, 1976a).

We would like to thank N. Boll and B. Schimpf for excellent technical assistance and Drs. J. B. Mercer and E. Simon for their suggestions on the manuscript.

\section{REFERENCES}

Fitzgerald, O. (1940) Discharges from the sensory organs of cat's vibrissae and the modification in their activity by ions. J. Physiol. (Lond.), 98: 163-178.

Hellon, R. F. (1971) The marking of electrode tip positions in nervous tissue. J. Physiol.

Vol. 30, No. 6, 1980 
(Lond.), 214: 12P.

Hellon, R. F. and Misra, N. K. (1973a) Neurones in the dorsal horn of the rat responding to scrotal temperature changes. J. Physiol. (Lond.), 232: 375-388.

Hellon, R. F. and Misra, N. K. (1973b) Neurones in the ventrobasal complex of the rat thalamus responding to scrotal skin temperature changes. J. Physiol. (Lond.), 232: 389399.

Hellon, R. F. and Mitchell, D. (1975) Convergence in a thermal afferent pathway in the rat. J. Physiol. (Lond.), 248: 359-376.

Hellon, R. F., Hensel, H., and Schäfer, K. (1975) Thermal receptors in the scrotum of the rat. J. Physiol. (Lond.), 248: 349-357.

Hensel, H. and SCHÄFER, K. (1974) Effects of calcium on warm and cold receptors. Pflügers Arch., 352: 87-90.

NeYA, T. and Pierau, Fr.-K. (1975) Dorsal horn cell activity to thermal stimulation of rat's scrotal skin. Pflügers Arch. (Suppl.), 359: R97.

Neya, T. and Pierau, Fr.-K. (1976a) Vasomotor response to thermal stimulation of the scrotal skin in rats. Pflügers. Arch., 363: 15-18.

Neya, T. and Pierau, Fr.-K. (1976b) Effect of calcium on the response of dorsal horn neurons to temperature stimulation of rat's scrotal skin. Pflügers Arch. (Suppl.), 362: R51.

NIER, K. (1974) Effects of different ionic components on afferent responses of vibrissa receptors. Pflügers Arch., 347: 27-38.

Pierau, Fr.-K. and Wurster, R. D. (1975) Effects of ouabain and calcium on temperature responses of cold receptors of the cat tongue. Pflügers Arch. (Suppl.), 359: R97.

Pierau, Fr.-K., Torrey, P., and CARPenter, P. O. (1975) Afferent nerve fiber activity responding to temperature changes of the scrotal skin in the rat. J. Neurophysiol., 38: 601-612.

Pierau, Fr.-K., Wurster, R. D., Neya, T., Yamasato, T., and Ulrich, J. (1980) Generation and processing of peripheral temperature signals in mammals. Int. J. Biometeorol., 24 : in press.

Sumino, R., Dubner, R., and Starkman, S. (1973) Responses of small myelinated warm fibers to noxious heat stimuli applied to the monkey's face. Brain Res., 62: 260-263.

Willis, W. D. and Coggeshall, R. E. (1978) Sensory Mechanisms of the Spinal Cord, Plenum Press, New York and London.

Yamasato, T. and Pierau, Fr.-K. (1979) Multimodal temperature reaction of dorsal horn neurones of rats. Pflügers Arch. (Suppl.), 382: R36. 